\title{
Effect of body composition intake with nano-lactic acid in
}

\section{rats}

Takayuki Watanabe $^{1}$, Takeshi Sato ${ }^{2 *}$, Masami Miyazaki ${ }^{3}$ and Shoji Igawa ${ }^{4}$

${ }^{1}$ Hachinohe Gakuin University, Japan

${ }^{2}$ Jissen Women's University, Japan

${ }^{3}$ Waseda University, Japan

${ }^{4}$ Nippon Sport Science University, Japan

\begin{abstract}
Prebiotic effect and probiotics lactobacillus were to one of the most famous effect-efficacy of the health conditions. It is important to reduce adult diseases risk for public health based politics. Especially in East Asian people, there were increasing the health problems related to being obsess by attributed to the Westernization of daily meals. The purpose of this study was to investigate the effect of nano-lactic acid feeding as lactobacillus in rat fed a high-fat diet, to prevention of increased body fat percentage. Male Wistar rats were individually housed in cages at temperature of $23 \pm 1$ degree centigrade, and $40-60 \%$ humidity. After basically 2 weeks breeding on pear feeding, 20 rats were divided 4 groups each 5 rats and were fed same calorifacient pear feeding diet and water, control (group: C) as high-carb meal, Japanese style, C with high levels lactobacillus (group: CL), high-fat same calorifacient feed and water (group: F), F with high levels lactobacillus (group: FL), all feed certain time once a day. It was delivered the lactobacillus 500 billion per $1 \mathrm{cc}$ by oral radio sonde tube. This animal experiment was carried out in accordance with the Japanese law, which allows experiments on laboratory animals in Nippon Sport Science University accordance to the principle of laboratory animal care. After experimental feed, it was measured lipid metabolism based in lean body mass. It was showed that induced high level lactobacillus were to block the adipose tissue fat mass. There were significantly increasing the body fat percentage in $\mathrm{F}$ compare to $\mathrm{C}$ in spite of pair feeding same calorie. However there were no significant difference in body mass in between $\mathrm{F}$ and $\mathrm{C}$. Consequently, it was recommended to preactive intake of the nano-lactobacillus because possibility of inhibit to accumulated fat mass with high fat food. However it was inactive lactic acid because of heat-treated. Therefore, it is expected the highly-concentrated lactic bacterium as same as fiber rich diet for human.
\end{abstract}

\section{Introduction}

Obesity has become one of the problems in the world [1-5]. According to World Health Organization, rate of obesity has more than doubled since 1980. In 2014, more than 1.9 billion adults 18 years and older were overweight, and of those over 600 million adults were obese. $\mathrm{Ng}$ et al. [6] was reported to population of adults with body-mass index of $25 \mathrm{~kg} / \mathrm{m}^{2}$ or grater increased between 1980 to 2013 from $28.8 \%$ to $36.9 \%$ in men, and from $29.8 \%$ to $38.0 \%$ in women, and prevalence of overweight or obese has increased in children and adolescents both developed country and developing country [6]. Obesity is regarded to excess accumulated of adipose tissue in the body by a lack of exercise and improper eating habits. Especially abdominal fat accumulation is one of the major risk factor for the various diseases, including diabetes [7], cardiovascular disease [8], hyperlipidemia, hypertension and chronic kindly disease [9]. Especially in East Asian people, there were increasing the health problems related to being obsess by attributed to the Westernization of daily meals. Obesity is a result of imbalance between the energy consumption and energy intake, it is necessary to control body weight to consume energy to adequate levels of physical activity [10], and to reduce energy intake [11] increased to such a highfat diet.

Lactic acid bacteria are widely distributed in nature from agricultural and livestock products to inside the body of human and animal. Effect of lactic acid bacteria was considered that affect to useful substance production and intestinal flora to remain the intestinal as living microbe, and bacterial components or metabolite acts to organism directly. Bacteria used as probiotics are mainly lactic acid bacteria, probiotics was defined as 'A live microbial feed supplement which beneficially affects the host animal by improving its intestinal microbial balance' by Fuller [12]. Probiotic was effected health condition, Isolauri et al. [13] reported, children of atopic eczema given probiotic-supplemented formulas ware occurred improvement skin condition as compared unsupplemented children, and reduction in the concentration of soluble CD4 in serum and eosinophilic protein $\mathrm{X}$ in urine [13]. Also, probiotics were shown to be effective in the maintenance of remission therapy targeting colonic inflammation in ulcerative coltis or pouchitis patients [14], and to be alleviated symptom of pollinosis when yogurt supplemented with a probiotic strain was given to moderate Japanese cedar pollinosis patients [15], lactic acid bacteria as probiotics was found to have immunomodulatory effects. These effect are effectiveness of probiotic strain, it has been confirmed to even effect in the heat-killed lactic acid bacteria [16]. In addition, these lactic acid bacteria are potentially to be suppressed the increase of weight gain and body fat [17]. The purpose of this study was to investigate the effect of nano-lactic acid feeding in rat fed a high-fat diet, to prevention of increased body fat percentage.

Correspondence to: Takashi Sato, $\mathrm{PhD}, 4-1-1$, Osakaue Hino, Tokyo 191-8510, Japan, E-mail: Sato-takeshi@jissen.ac.jp

Key words: nano-lactic acid, body composition

Received: March 23, 2015; Accepted: April 09, 2015; Published: April 11, 2015 


\section{Materials and methods}

\section{Experimental procedure}

Wistar rats were individually housed in cages at temperature of 23 \pm 1 degree centigrade, and 40-60\% humidity. After basically 2 weeks breeding on pear feeding, 20 rats were divided 4 groups each 5 rats and were fed same calorifacient pair feeding diet and water, control (group: C) as high-carb meal (344 kcal/100g), Japanese style, high-carb meal with high levels lactobacillus (group: CL), high-fat same calorifacient feed $(597 \mathrm{kcal} / 100 \mathrm{~g}$ ) and water (group: F), high-fat meal with high levels lactobacillus (group: FL), all feed certain time once a day. It was delivered the lactobacillus 500 billion per 1cc by oral radio sonde tube. This animal experiment was carried out in accordance with the Japanese law, which allows experiments on laboratory animals in Nippon Sport Science University accordance to the principle of laboratory animal care. During the experimental period of two weeks body weight was measured every one week. After two weeks of experimental feed, there were measured percent of body fat and muscle mass of leg.

\section{Statistical analysis}

Experimental data were expressed as mean values with standard deviation. Weight data of statistical analysis was used two-way analysis of variance (ANOVA). \%body fat in the abdominal cavity and muscle mass data of statistical analysis was used one-way ANOVA. Difference in mean values were assessed with Turkey's HSD multiple comparison procedure. Statistical significance was considered at $p<0.05$.

\section{Results}

Body weight of rats were significant increesed in all groups on a weekly basis (Figure 1). As a result of the multiple comparisons, it was not significant difference that body weight befor starting this experiment between all groups. In addition, body weight after one week was not difference between all groups, too. CL weight after two week was significantly lower values as compared to C, F and FL. Two weeks of weight gain rate in rats, C had increased $38.9 \%$, CL had increased $31.4 \%$, F had increased $36.2 \%$, FL had incerased $37 \%$. CL was tendency lower than $\mathrm{C}(P=0.07)$, but there were not significant difference between all groups (Figure 2) Muscle mass was not significant difference for all group (Figure 3). Body fat percentage of C and CL were significant lower values as compared to F and FL (Figure 4).

\section{Discussion}

This study was to investigate the effect of nano-lactic acid feeding in rat. Body weight of any group of rat was increased. It was considered that energy intake of rat of all group was same, because change of body weight of $\mathrm{C}$ and $\mathrm{F}$ were not significant difference. Muscle mass was not
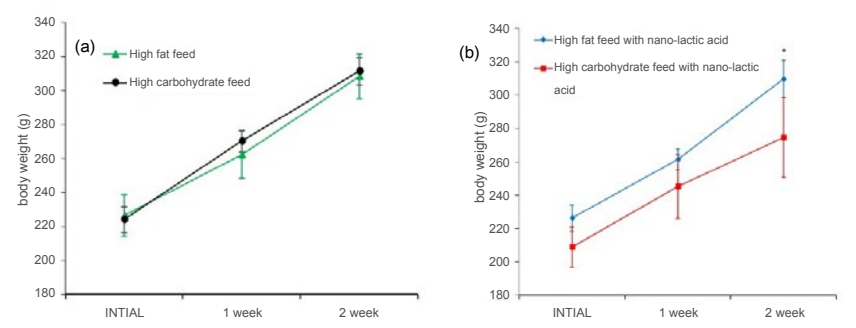

Figure 1. Change in body weight in rats with nano-lactic acid. (a) Changing body weight between high carbohydrate feed and high fat feed and (b) changing body weight high carbohydrate feed with nano-lactic acid and high fat feed with nano-lactic acid. ${ }^{*}: p<0.05$ vs $\mathrm{C}, \mathrm{F}$ and $\mathrm{FL}$

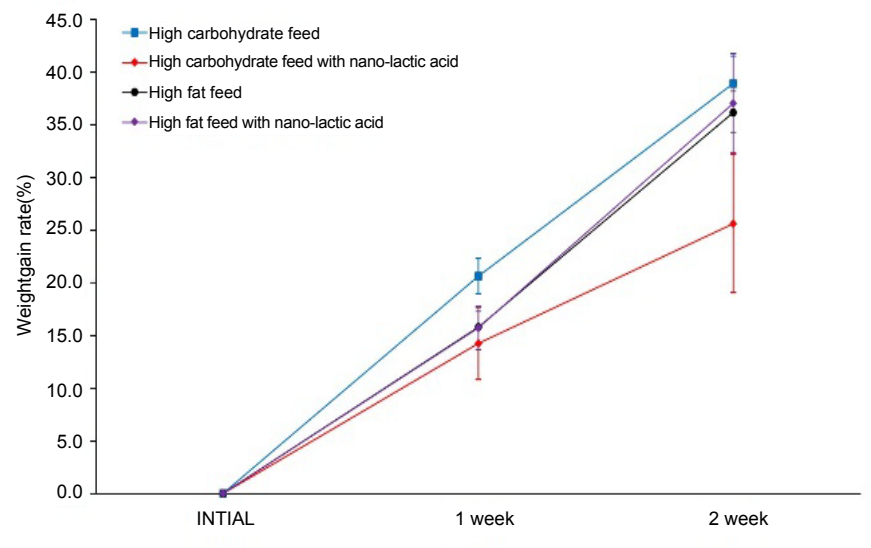

Figure 2. Chang in body weight gain rate between the groups.

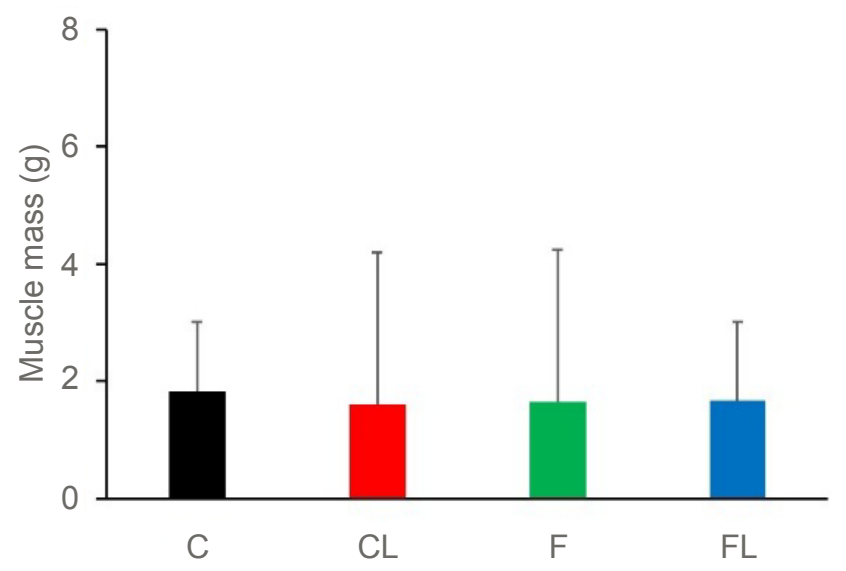

Figure 3. Comparison of muscle mass between the groups.

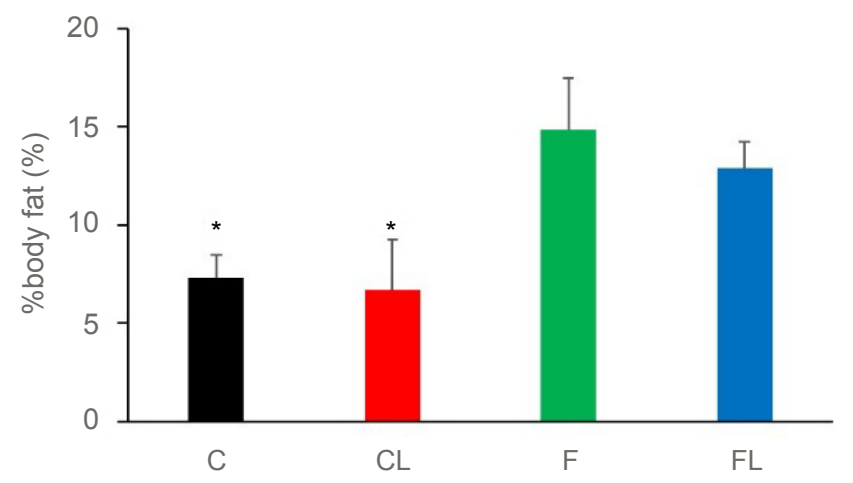

Figure 4. Comparison of \%body fat between the groups. *: $p<0.05$ vs $\mathrm{F}$ and FL.

difference between all group. This result was shown that there were no changed in the activity of rats into cage for all groups.

Body fat percentage of $\mathrm{C}$ was higher than $\mathrm{F}$. it was possible that occurred to change in gut microbiota. When fed the high-fat diet to wild-type mice, wild-type mice became obese, and including a decrease in Bacteroidetes and an increase in both Firmicutes and Proteobacteria constituting the gut microbiota [18]. The research that lead to obesity and diabetes by fed a high-fat/carbohydrate free diet in mice, changes number of bacterial in the gut microbiota, with reduction in Bifidobacterium species numbers, reduced Bacteroides related bacteria, 
Eubacterium rectale-Clostridium coccoides group content [19]. These researches show that high fat diet lead to change the gut microbiota constitution.

It was possibility that gut microbiota plays a role in obesity and energy metabolism. Bäckhed et al. [20] reported, compared to germ-free mice and conventionally raised mice holds normal intestinal bacteria, in spite of dairy consumption of feed was $29 \%$ less than germ-free mice, total body fat of conventionally raised mice was $42 \%$ greater and epididymal fat pad weight was $47 \%$ greater than germ-free mice. When colonized intestinal bacteria of conventionally raised mice to germ-free mice, $57 \%$ increase there in total body fat content and a $61 \%$ increase in epididymal fat weight at 14 days. Therefore, high fat diet groups ( $F$ and FL) was changed gut microbiota and increased accumulation of fat percentage than high carbohydrate groups (C and CL).

Weight gain rate of rat consumed nano-lactic acid bacteria feeding was not changed. However in recent study, it was reported that suppressive effect of accumulation of visceral adipose for probiotic intake [17]. In this report, subject with higher body mass index and abdominal visceral area were divided two groups, fermented milk containing Lactobacillus gasseri SBT2055 $\left(5 \times 10^{8} \mathrm{cfu} / \mathrm{g}\right)$ group and fermented milk group, and ingested 200g/day for 12 weeks. Befor and after the experiment, abdominal computed tomography scans for the calculating the visceral fat and subcutaneous fat area and measured waist circumference, fermented milk containing SBT2055 group was decreased $4.6 \%$ of visceral fat area, $3.3 \%$ of subcutaneous fat area and $1.8 \%$ waist circumference, by contrast, fermented milk group was not decrease these parameters.

Kondo et al. [21] was reported antiobesity effect to probiotic bifidobacterial strain in a mouse model with high-fat diet-induced obesity. In this report, induced obesity mice were fed a high fat diet supplemented with bifidobacterial breve B-3 at $10^{8}$ or $10^{9} \mathrm{CFU} / \mathrm{d}$ for 8 weeks, accumulation of body weight and epididymal fat were suppressed, and improved serum levels of total cholesterol, fasting glucose and insulin for supplemented bifidobacterial breve B-3 [21]. Also, Kang et al. [22] reported Anti-obesity effect of Lactobacillus gasseri BNR17 in high-sucrose diet-induced obese mice. Mice were divide to 4 group, fed a normal diet, high-sucrose diet, high-sucrose diet with Lactobacillus gasseri BNR17 $10^{9} \mathrm{CFU}$ and high-sucrose diet with Lactobacillus gasseri BNR17 $10^{10} \mathrm{CFU}$, and orally administered twice per day for 10 weeks, reduced body weight and white adipose tissue weight regardless of administered Lactobacillus gasseri BNR17 [22].

These result was supported antiobesity effects, in our study, body weight of high carbohydrate diet with nano-lactic acid bacteria (CL) was suppressed to high carbohydrate diet (C), however it was not changed high fat diet with lactic acid supplemented group (FL), because experimental period was short to suppression the body weight and fat. Experimental period of previous studies to use the mice were from 8 to 10 weeks, and weight gain suppression for high fat diet with lactic acid bacteria intake was expressed from 3 weeks. There is possibility that the nano-lactic acid bacteria supplemented effect was appeared by long to the experimental period.

\section{References}

1. Ahmadi M, Moosazadeh M, Vardanjani HM, Dehghan A (2014) Prevalence of obesity and overweight and their related factors among the adults of Mazandaran Province, Iran, in 2010. Electron Physician 6: 955-961. [Crossref]

2. Flegal KM, Carroll MD, Ogden CL, Curtin LR (2010) Prevalence and trends in obesity among US adults, 1999-2008. JAMA 303: 235-241. [Crossref]
3. Kumah DB, Akuffo KO, Abaka-Cann JE, Affram DE, Osae EA (2015) Prevalence of Overweight and Obesity among Students in the Kumasi Metropolis. Journal of Nutrition and Metabolism.

4. Neovius K, Johansson K, Kark M, Tynelius P, Rasmussen F (2013) Trends in selfreported BMI and prevalence of obesity 2002-10 in Stockholm County, Sweden. Eur J Public Health 23: 312-315. [Crossref]

5. Ning X, Zhan C, Yang Y, Yang L, Tu J, et al. (2014) Secular trends in prevalence of overweight and obesity among adults in rural Tianjin, China from 1991 to 2011: a population-based study. PLoS One 9: e116019. [Crossref]

6. Ng M, Fleming T, Robinson M, Thomson B, Graetz N, et al. (2014) Global, regional, and national prevalence of overweight and obesity in children and adults during 19802013: a systematic analysis for the Global Burden of Disease Study 2013. Lancet 384: 766-781. [Crossref]

7. Young TK, Dean HJ, Flett B, Wood-Steiman P (2000) Childhood obesity in a population at high risk for type 2 diabetes. J Pediatr 136: 365-369. [Crossref]

8. Thomas F, Bean K, Pannier B, Oppert JM, Guize L, et al. (2005) Cardiovascular mortality in overweight subjects: the key role of associated risk factors. Hypertension 46: 654-659. [Crossref]

9. Narkiewicz K (2006) Obesity and hypertension--the issue is more complex than we thought. Nephrol Dial Transplant 21: 264-267. [Crossref]

10. Jakicic JM, Otto AD (2005) Physical activity considerations for the treatment and prevention of obesity. Am J Clin Nutr 82: 226S-229S.

11. Swinburn B, Sacks G, Ravussin E (2009) Increased food energy supply is more than sufficient to explain the US epidemic of obesity. Am J Clin Nutr 90: 1453-1456.

12. Fuller R (1989) Probiotics in man and animals. J Appl Bacteriol 66: 365-378. [Crossref]

13. Isolauri E, Arvola T, Sütas Y, Moilanen E, Salminen S (2000) Probiotics in the management of atopic eczema. Clin Exp Allergy 30: 1604-1610. [Crossref]

14. Hörmannsperger G, Haller D (2010) Molecular crosstalk of probiotic bacteria with the intestinal immune system: clinical relevance in the context of inflammatory bowel disease. Int J Med Microbiol 300: 63-73. [Crossref]

15. Xiao JZ, Kondo S, Yanagisawa N, Takahashi N, Odamaki T, et al. (2006) Effect of probiotic Bifidobacterium longum BB536 [corrected] in relieving clinical symptoms and modulating plasma cytokine levels of Japanese cedar pollinosis during the pollen season. A randomized double-blind, placebo-controlled trial. J Investig Allergol Clin Immunol 16: 86-93. [Crossref]

16. Harima-Mizusawa N, Iino T, Onodera-Masuoka N, Kato-Nagaoka N, KiyoshimaShibata J, et al. (2014) Beneficial Effects of Citrus Juice Fermented with Lactobacillus plantarum YIT 0132 on Japanese Cedar Pollinosis. Biosci Microbiota Food Health 33: 147-155. [Crossref]

17. Kadooka Y, Sato M, Imaizumi K, Ogawa A, Ikuyama K, et al. (2010) Regulation of abdominal adiposity by probiotics (Lactobacillus gasseri SBT2055) in adults with obese tendencies in a randomized controlled trial. Eur J Clin Nutr 64: 636-643. [Crossref]

18. Hildebrandt MA, Hoffmann C, Sherrill-Mix SA, Keilbaugh SA, Hamady M, et al. (2009) High-fat diet determines the composition of the murine gut microbiome independently of obesity. Gastroenterology 137: 1716-1724. [Crossref]

19. Delzenne NM, Cani PD (2010) Nutritional modulation of gut microbiota in the context of obesity and insulin resistance: Potential interest of prebiotics. Int Dairy $J$ 20: 277-280.

20. Bäckhed F, Ding H, Wang T, Hooper LV, Koh GY, et al. (2004) The gut microbiota as an environmental factor that regulates fat storage. Proc Natl Acad Sci U S A 101: 15718-15723. [Crossref]

21. Kondo S, Xiao JZ, Satoh T, Odamaki T, Takahashi S, et al. (2010) Antiobesity effects of Bifidobacterium breve strain B-3 supplementation in a mouse model with high-fat diet-induced obesity. Biosci Biotechnol Biochem 74: 1656-1661. [Crossref]

22. Kang JH, Yun SI, Park MH, Park JH, Jeong SY, et al. (2013) Anti-obesity effect of Lactobacillus gasseri BNR17 in high-sucrose diet-induced obese mice. PLoS One 8: e54617. [Crossref]

Copyright: (C)2015 Watanabe T. This is an open-access article distributed under the terms of the Creative Commons Attribution License, which permits unrestricted use, distribution, and reproduction in any medium, provided the original author and source are credited. 